\title{
AN ANATOMICAL STUDY OF MEDIAN AND ULNAR NERVE COMMUNICATION IN THE FOREARM
}

\author{
Rajasri Chunder *1, Amita Sarkar ${ }^{2}$.
}

${ }^{{ }_{1}}$ Associate Professor, Department Of Anatomy, Jagannath Gupta Institute Of Medical Sciences And Hospital, K.P Mondal Road, Buita, Budge Budge, Kolkata, India.

${ }^{2}$ Assistant Professor, Department Of Anatomy, K. P. C. Medical College \& Hospital, 1f, Raja S.C.Mullick Road, Jadavpur, Kolkata, India,

\section{ABSTRACT}

Background: Communications between nerves are relatively common, and individual variations in their anatomical organization have been described in various studies. Knowledge of the prevalence of such variations is necessary when establishing the diagnosis of neuropathies and surgical landmarks. This study has as purpose to report the incidence, type, topography of the presence of median and ulnar nerve communication in the forearm

Materials and Methods: Anatomical dissection of 30 forearms procured from 15 formalin preserved cadavers was carried out in the Department of Anatomy, K.P.C Medical College and Hospital, Kolkata to demonstrate the incidence, type, topography of the anastomotic branch and the length was measured with a measuring tape. A photograph of the anomaly was also taken.

Results: The anastomosis was found in only two cases (6.6\%). Both the cases the communication was unilateral. Conclusion: The Median and Ulnar nerve anastomosis has been extensively observed by anatomic and electromyographic studies. Understanding the existence of this variation, its location and its possible presentation is important to help physicians and hand surgeons to understand both anatomic variations and paradoxical complaints of sensory and motor loss of patients.

KEY WORDS: Median nerve, Ulnar nerve, Martin-Gruber Anastomoses, anomalous innervations.

Address for Correspondence: Dr. Rajasri Chunder, Associate Professor, Department Of Anatomy, Jagannath Gupta Institute Of Medical Sciences And Hospital, K.P Mondal Road, Buita, Budge Budge, Kolkata 700137, India. E-Mail: rajasrichunder@yahoo.com

\section{Access this Article online}

\section{Quick Response code}

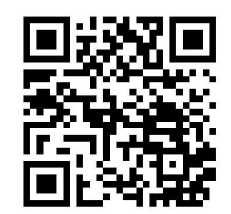

DOI: $10.16965 /$ ijar.2017.412

Web site: International Journal of Anatomy and Research

ISSN 2321-4287

www.ijmhr.org/ijar.htm

Received: 11 Aug 2017

Peer Review: 11 Aug 2017

Revised: None
Accepted: 03 Oct 2017

Published (O): 01 Nov 2017

Published (P): 01 Nov 2017

\section{INTRODUCTION}

Following several studies, two types of communications between median and ulnar nerve was found in the forearm. Branches between the median nerve or sometimes the anterior interosseous nerve may arise above and pass downwards and medially between flexors digitorum superficialis and profundus, deep to the ulnar artery, to join the ulnar nerve and it is called Martin-Gruber anastomosis (MGA) [1].
Martin, a Swedish anatomist was the first one to notice the connection between the nerve fibres of the median and ulnar nerves in the forearm [2]. In 1870, Gruber found 38 such communications after dissecting 250 forearms (15.2\%). Thus, the anastomosis is known as Martin-Gruber anastomosis [3]. It can arise from the median nerve directly or the anterior interosseous nerve or the branches destined to supply the deep flexor muscle of the fingers 
proximally and communicate with the ulnar nerve distally [4].

Another type of anastomosis has been encountered in the forearm. Here, the anastomotic branch arises proximally in ulnar nerve and joins distally with the median nerve, and is called Martin-Gruber reverse anastomosis or Marinacci communication. Marinacci found a patient with traumatic median nerve injury in the forearm with intact innervations of the hand muscles supplied by the median nerve; though there was associated denervation of the flexor muscles in forearm [5]. This anastomosis is less frequent. The median and ulnar nerve communications in the palm are Riche-Cannieu anastomosis and Berretini Anastomosis. The incidence of Martin Gruber connection ranges between $5 \%$ to $40 \%$, with an average of $17 \%$ [6]. Most of these connections from the median nerve to the ulnar nerve are unilateral, whereas bilateral in about $10-40 \%$ of the cases [7]. Martin Gruber connection was more common and found bilaterally in cases of trisomy 21 [8]. When present, isolated ulnar and median nerve lesions may produce unpredictable pattern of intrinsic muscle paralysis owing to median nerve innervation of a variable number of intrinsic muscles of the hand [9]. No sexual differences in the incidence of the anomaly has been reported [10]. This anomaly seems to be inherited in autosomal dominant mode [11].

\section{MATERIALS AND METHODS}

A total number of 30 forearms from 15 formalin preserved cadavers ( 3 females, 12 males aged between 50- 70 years of age) were carefully dissected to demonstrate median and ulnar nerve communication in the Department of Anatomy, K.P.C Medical College and Hospital, Kolkata. The forearms selected were not deformed due to injury, malformation or scarring. The dissection was done by giving a midline incision in the forearm and a lower third of the arm and reflecting the skin along superficial and deep fasciae to the radial and ulnar sides respectively, to expose the forearm muscles. The superficial muscles of the forearm were retracted and the presences of any communication between the nerves of the forearm were analyzed. Photographs of the dissected forearms were then taken to demonstrate the anomaly and show their relation with adjacent structures. The size of the anastomosis was measured by a measuring tape. Any other anomalies- muscular, vascular or neural were also noted.

\section{RESULTS}

The presence of Martin-Gruber anastomosis was demonstrated in two of the thirty dissected forearms (6.6\%), one being on the left side (3.3 $\%)$ (Fig 1) and one of the right side (3.3\%) (Fig 2).The average size of the anastomotic branch from its origin to the junction with ulnar nerve was $6.6 \mathrm{~cm}$ (Table 1). Topographically, both the communicating branches originated from the median nerve proximally. One of the branches originated from the median nerve at the level of the elbow (Fig 1) and the second one originated about $2.5 \mathrm{~cm}$ below the elbow. (Fig 2) In both cases, the branches followed an oblique path from its origin, passing deep to the ulnar artery. Both the branches passed between the superficial and deep flexor muscles of the fingers. In both cases, there was only one anastomotic branch which joined the ulnar nerve. One of the specimens was associated with vascular anomalies (Fig 2).

The brachial artery had a normal course upto the cubital fossa; it then divided into radial artery and a common trunk which passed deep to the ulnar head of pronater teres. The common trunk gave rise to the ulnar recurrent branch and then trifurcated into three branches from medial to lateral: one branch followed the course of ulnar artery accompanied by the ulnar nerve on its medial side, second branch-posterior interosseous artery had a short course in the flexor compartment, third branch- anterior interosseous artery passed down in front of the interosseous membrane along with the anterior interosseous nerve. The other upper limbs in both cases revealed no abnormalities.

Table 1: Topography and measurements of the medianulnar anastomoses found in the study.

\begin{tabular}{|c|c|c|c|c|c|}
\hline S. no. & Side & $\begin{array}{c}\text { Number of } \\
\text { branch }\end{array}$ & Direction & $\begin{array}{c}\text { Proximal nerve of } \\
\text { origin }\end{array}$ & $\begin{array}{c}\text { Measurement } \\
(\mathrm{cm})\end{array}$ \\
\hline 1 & Left & 1 & $\begin{array}{c}\text { Downwards and } \\
\text { medially }\end{array}$ & Median nerve & 2.9 \\
\hline 2 & Right & 1 & $\begin{array}{c}\text { Downwards and } \\
\text { medially }\end{array}$ & Median nerve & 3.7 \\
\hline
\end{tabular}


Fig. 1: Flexor aspect of right forearm showing a communicating branch (CB) extending downwards and medially from the median nerve (MN) at the level of elbow to the ulnar nerve (UN) between the superficial flexor muscles (SFM) and deep flexors.

Fig. 2: Flexor aspect of left forearm showing a communicating branch (CB) extending downwards and medially from the median nerve ( $\mathrm{MN}$ ) in the upper part of the forearm passing deep to the ulnar artery(UA) lying between the superficial flexor muscles (SFM) and deep flexors joining the lateral side of the ulnar nerve(UN) in the middle third of the arm. The brachial artery (BA) divided into radial artery (RA) and a common trunk (CT). The common trunk (CT) gave rise to the ulnar recurrent branch and then trifurcated into three branches from medial to lateral: one branch followed the course of ulnar artery (UA) with the ulnar nerve (UN) on its medial side, second branch- posterior interosseous artery (PIA) had a short course in the flexor compartment, third branch- anterior interosseous artery (AIA) passed down along with the anterior interosseous nerve.

\section{DISCUSSION}

The knowledge of this anatomical variation cannot be overlooked by practitioners considering our lack of availability of various diagnostic tools such as special imaging and electrodiagnostic procedures. These anomalies can therefore lead to incorrect diagnosis of nerve injuries which results in ineffective treatments. Martin Gruber connection or median-to-ulnar nerve communication in the forearm is a frequently encountered
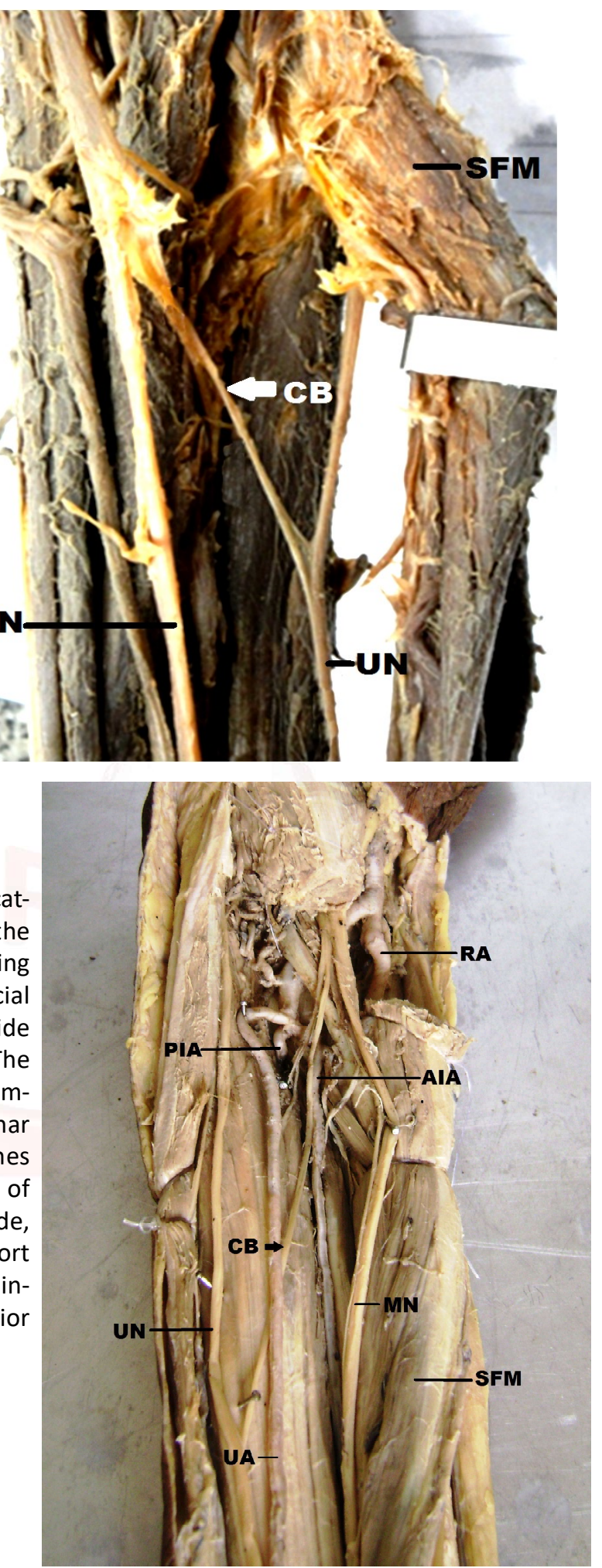

anomaly. The incidence of Martin-Gruber anastomosis was described by Gruber [3] as (15.2\%), Kimura et al. [7] (17\%), Uchida et al [12] (17\%), Amoiridis [13] (32\%), Nakashima [4] (21.3\%), Shu et al. [14] (23.6\%), Rodriguez-Niedenfuhr [6] (13.6\%), Erdem et al. [15] (27\%), Sarikcioglu et al., [16] Prates et al. [10] (7.8\%), Lee et al. [17] (39\%), Kazaros et al. [18] (10\%), Almeida et al., [19] and Felippe et al. [20] (10\%). In our study,the incidence is $6.6 \%$. There is a little variation 
regarding the laterality of the anastomosis. Some studies report its right predominance (Nakashima et al [4]; Shu et al. [14], Sarikcioglu et al. [16], Felippe et al [20]), whereas some others reported left side dominance (Almeida et al [19]; Lee et al. [17]). Kimura et al [7] reported a majority of bilateral cases while Taams [21] and Prates et al [10] did not find any significant differences between both sides as in our study.

Various researchers have classified this anomaly into different types according to their origin, course, topography and supply. Leibovic et al [9] described four types of Martin Gruber connection- $60 \%$ are type I, sending motor branches from the median to the ulnar nerve to innervate median muscles; $35 \%$ are type II, sending motor branches from median to ulnar nerves to innervate ulnar muscles; $3 \%$ are type III, sending motor fibers from the ulnar to the median nerve to innervate median muscles; and $1 \%$ are type IV, sending motor fibers from the ulnar to the median nerve to innervate ulnar muscles [6].

Nidenfuhr et al., [6] studied of 70 human cadavers and classified Martin-Gruber anastomosis in 2 patterns with each pattern being further subdivided into 3 types as follows: Pattern IAnastomosis by one branch, Pattern II- Anastomosis by two branches. Both these patterns are further classified into 3 types, each depending upon origin of the anastomotic branch from median nerve or its branches as follows: Type a- anastomotic branch originates from branch to superficial forearm flexors-47.3\%. Type $b$ anastomotic branch originates from main trunk of median nerve-10.6\%. Type c- anastomotic branch originates from anterior interosseous nerve-31.6\%. In our study both the cases presented a Pattern I b type of anastomosis.

Cavalheiro et al [22] classified the anastomosis into six types based on cadaveric study of 100 forearms : type I: anastomosis between the anterior interosseous branch of median nerve and the ulnar nerve ; type II: anastomosis between the anterior interosseous branch of median nerve and the ulnar nerve by two branc hes (double anastomosis); type III: anastomosis between the median nerve and the ulnar nerve; type IV: anastomosis between branches of the median nerve (destined for the flexor digitorum profundus muscle of the fingers) and ulnar nerve; these fascicles form a loop with distal convexity ; type $\mathrm{V}$ : intramuscular anastomosis ; and type VI: anastomosis between a branch of the median nerve (destined to the flexor digitorum superficialis muscle) and the ulnar nerve. According to this classification, our study showed Type III in both the cases.

In our study, in both cases the anastomotic branches laid between the flexor digitorum superficialis and flexor digitorum profundus muscles. Similar findings were found in various other studies, while Caeteno et al, [23] Verchere et al [24] and Nakashima et al [4] reported intramuscular anastomoses that passed within the flexor digitorum profundus muscle. Nakashima, Caeteno even believed that these anastomotic nerve fibres were destined to supply the flexor digitorum profundus muscle contrary to the other authors, who believed that the anastomotic branch supplied the intrinsic muscles of the thumb and the first dorsal interossei. Several electrophysiological studies demonstrated a greater incidence of supply to the first dorsal interossei $[12,15,25]$. In our study, the anastomostic branch in both cases passed deep to the ulnar artery. This is in compliance to most of the studies. Prates studied 32 forearms and reported 2 cases where the anastomotic branch passed superficial to the ulnar artery [10].

Research has cited the importance of Martin Gruber connection in different clinical scenarios. In presence of such anastomosis, median nerve lesions in the hand may present with partially or completely unaffected intrinsic muscles of the hand. Carter et al described such a patient presenting with partial thenar muscle atrophy associated with bilateral symptomatic carpal tunnel syndrome. The patient had severe atrophy of his Abductor Pollicis Brevis on one side and less severe atrophy on the other side. The functions of the other muscles of the thenar eminence were relatively intact inspite of compromised sensory symptoms due to bilateral carpal tunnel syndrome. The mechanism of this partial thenar muscle preservation would be that the anastomotic nerve fibers that had crossed over from the median nerve to the ulnar nerve in the forearm ran unimpeded to the muscles of the thenar eminence so that their 
muscle bulk and function was preserved [26].

Brandsma et al described two clinical cases, with complete rupture of the ulnar nerve at the elbow and median nerve injury in the wrist, secondary to leprosy neuropathy. The function of the first dorsal interosseous muscle and the flexor pollicis brevis were retained along with absence of typical clawing of fingers as observed in median and ulnar nerve lesion. These findings were attributed to the presence of Martin-Gruber anastomosis [27].

Although some research claims that the cross over fibres are purely motor in nature, other studies consider the possibility of sensory fiber crossover as well [7]. So abnormal symptoms of sensory radiation may be produced [28]. Shafic et al. reported the case with symptomatic carpal tunnel syndrome, having negative results in provocative tests such as Tinel's sign and Phalen's test. This patient on the otherhand, presented evident signs of ulnar nerve compression in the elbow. Nerve stimulation in the epitrochlear-olecranon groove triggered the typical symptoms of carpal tunnel syndrome, which confirmed the transfer of sensory nerve fibres from the ulnar nerve to the median nerve [29].

In our study, one of the specimen (Fig: 2 ) is associated with vascular anomaly - with the brachial artery division into radial artery and a common trunk which gave rise to three branches from medial to lateral: one branch followed the course of ulnar artery along with the ulnar nerve medially, second branch- posterior interosseous artery had a short course in the flexor compartment, third branch- anterior interosseous artery. Review of literature has revealed a case report of superficial ulnar artery in the same extremity where Martin Gruber connection is present [30].

\section{CONCLUSION}

It is clear from the present study, that the median -ulnar anastomosis though a relatively common finding may present in unusual manner with discrepancies between the history and the physical examination. Wherever neurological symptoms exist, a thorough clinical examination of the peripheral nerves must be conducted and if possible should be confirmed with electrodiagnostic studies. The knowledge of the existence of the anastomosis between the median and ulnar nerves in forearm, its types of presentation and its anatomical disposition is extremely important for the correct diagnosis of neuropathies (Carpal tunnel, Cubital tunnel, Leprosy neuropathy). In addition, it is essential to differentiate complete nerve damage from a partial injury of a peripheral branch to prevent complications in surgical procedures. In this way we can give better patient care.

\section{Conflicts of Interests: None}

\section{REFERENCES}

[1]. Standring S. Ellis H, Healy JC, Johnson D, Williams A. Gray's Anatomy. In: Thorax. Johnson D. (edr). 40 th edition. Elsevier Churchill Livingstone, Edinburgh. 2005; 883.

[2]. Martin, R. Tal om Nervus alimanna Egenskaper I Maniskans Kropp. Las Salvius, 1763.

[3]. Gruber, W. Ueber die Verbindung des Nervus medianu$s$ mit dem Nervus ulnaris am Unterame des Menschen um der Saugethiere. Archives of Physiology. 1870;37(2):501-522.

[4]. Nakashima, T. An anatomic study on the MartinGruber anastomosis. Surgical and Radiologic Anatomy .1993;15:193-195.

[5]. Marinacci, A. The problem of unusual anomalous innervations of hand muscles:the value of electrodiagnosis in its evaluation. Bulletin of the Los Angeles Neurological Society. 1964;29:133-142.

[6]. Rodriguez-Niedenführ M, Vazquez T, Parkin I, Logan B, Sañudo JR.Martín-Gruber anastomosis revisited. Clin. Anat. 2002;15:129-134.

[7]. Kimura J., Murphy M.J., Varda D.J.Electrophy siological study of anomalous innervation of intrinsic hand muscles. Arch. Neurol. 1976;33:842844.

[8]. Srinivasan R, Rhodes J. The median-ulnar anastomosis (Martin-Gruber) in normal and congenitally abnormal foetuses. Arch Neurol. 1981 Jul;38(7):4189.

[9]. Leibovic SJ, Hastings H .Martin-Gruber revisited. J. Hand Surg. 1992;17:47-53.

[10].Prates LC, Carvalho VC, Prates JC, Langone F, Esquisatto MAM. The Martin Gruber anastomosis in Brazilians: An anatomical study. Braz. J. morphol. Sci. 2003;20(3):177-180.

[11]. Crutchfield CA, Gutmann L. Hereditary aspects of median-ulnar nerve communications. J. Neurol.Neurosurg. Psychiatry. 1980;43:53-55.

[12]. Uchida Y, Sugiota Y. Electrodiagnosis of MartinGruber anastomosis. J Hand Surg. 1992;17:47-53.

[13]. Amoiridis G. Median-ulnar nerve communications and anomalous innervation of the intrinsic hand muscles: an electrophysiological study. Muscle Nerve. 1992;15:576-579. 
[14]. Shu H.S., Chantelot C., Oberlin C., Alnot J.Y., Shao H. Martin-Gruber commu-nicating branch: Anatomical and histological study. Surg. Radiol. Anat. 1999;21:115-118.

[15]. Erdem HR, Ergun S, Erturk C, Ozel S. Electrophysiological evaluation of the incidence of MartinGruber anastomosis in healthy subjects. Yonsei Med. J. 2002;43:291-295.

[16]. Sarikcioglu L., Sindel M., Ozkaynak S., Aydin H. Median and ulnar nerve com-munication in the forearm: an anatomical and electrophysiological study. Med. Sci. Monit. 2003;9:351-356.

[17]. Lee K.S., Oh C.S., Chung I.H., Sunwoo I.N. An anatomic study of the Martin- Gruber anastomosis: electrodiagnostic implications. Muscle Nerve. 2005;31:95-97.

[18].Kazakos K.J., Smyrnis A., Xarchas K.C., Dimitrakopoulova A., Veretas D.A. Anastomosis between the ulnar and median nerves and literature review. Acta Orthop. Belg. 2005;71:29-35.

[19]. Almeida J.A., Vitti M., Garbino J.A. Estudo anatómico da anastomose de Mar-tin-Gruber. Hansen Int. 1999;24:15-20.

[20]. Felippe M.M., Telles F.L., Soares A.C., Felippe F.M. Anastomosis between medi-an nerve and ulnar nerve in the forearm. J. Morphol. Sci. 2012;29:2326.

[21]. Taams KO. Martin-Gruber connections in South Africa. An anatomical study. J. Hand Surg. 1997;22B:328-330.

[22]. Cavalheiro CS, Filho MR, Pedro G, Caetano MF, Vieiraa LA, Caetano EB. Clinical repercussions of Martin-Gruber anastomosis: anatomical study.Rev Bras Ortop. 2016;51(2):214-223.
[23]. Caetano E.B, Vieira L.A, Caetano M.F, Cavalheiro C.S, Filho M.R, NetoJ.J.S. Intramuscular Martin-Gruber Anastomosis. Acta Ortop Bras. 2016;24(2):94-7.

[24].Verchere F. Note sur innervation des muscles fléxisseurs communs des doigts. Anastomose du nerf median et du nerf cubital. Union Med. 1883;35:205-7.

[25]. Wilbourn AJ, Lambert E. The forearm median to ulnar nerve communication: electrodiagnostic aspects. Neurology 1976;26:368.

[26]. Carter W., Murphy D., Armendariz R.Partial Thenar Atrophy as a Physical Manifestation of Martin Gruber Anastomosis. Rev. Ecuat. Neurol. 2013;22:13.

[27]. Brandsma JW, Birke JA, Sims DS. The Martin-Gruber innervated hand. J Hand Surg. 1986;11A:536-39.

[28]. Simonetti S. Electrophysiological study of forearm sensory fibre crossover in Martin-Gruber anastomosis. Muscle Nerve.2001;24:380-386.

[29]. Shafic A, Moussalen C, Stafford J. Cubital tunnel syndrome presenting with carpal tunnel symptoms: clinical evidence for sensory for median to ulnar nerve communication. Am J Orthop. 2009;38 (6): 104-6.

[30].Isakoviæ E, Deliæ J, Bajtareviæ A. Martin-gruber Anastomosis and Transposition in Cubital Tunnel. Bosnian Journal of Basic Medical Sciences .2007;7(1):71-73

\author{
How to cite this article: \\ Rajasri Chunder, Amita Sarkar. AN ANATOMICAL STUDY OF \\ MEDIAN AND ULNAR NERVE COMMUNICATION IN THE \\ FOREARM. Int J Anat Res 2017;5(4.2):4600-4605. DOI: 10.16965/ \\ ijar.2017.412
}

